\title{
A FRONTEIRA DA REALIDADE: RELAÇÃO DE PODER E RECONHECIMENTO TERRITORIAL EM CARTOGRAFIAS SOCIAIS
}

\author{
THE FRONTIER OF REALITY: \\ RELATIONS OF POWER AND \\ TERRITORIAL ACKNOWLEDGEMENT \\ IN SOCIAL CARTOGRAPHIES
}

Poliana Nascimento

polianadsn@gmail.com

Doutoranda em Antropologia pela UFPE

Pesquisadora do Projeto Nova Cartografia Social da Amazonia (PNCSA) /Grupo de Estudos Socioeconômico da Amazônia (GESEA) e do Laboratório de Estudos sobre Ação Coletiva e Cultura (LACC/UPE)

\section{RESUMO}

Esse artigo tem como fundamental ponto de exposição destacar as diferentes relações de poder que permeiam a percepção do território através da elaboração de mapas oficiais organizados para manter o controle territorial pelo Estado; e mapas construindo a partir da relação de pertencimento e conhecimento territorial em territórios pertencentes a povos e comunidades tradicionais destacados em cartografias sociais. Tais cartografias sociais refletem formas de apropriação do conhecimento sobre o território que povos e comunidades tradicionais carregam, colocando em evidência a realidade que desejam destacar. A maneira como expressam suas realidades simbólicas ou territoriais em suas autocartografias garante, por intermédio destas, um mecanismo de confrontação e de controle de seus próprios territórios em oposição às informações divulgadas por órgãos oficiais.

Palavras-chave: Território. Cartografia. Poder.

\begin{abstract}
This article highlights the different relations of power that permeate the perception of territory in the elaboration of official maps-organized to maintain territorial control by the State-and of maps constructed based on relationships of belonging and territorial knowledge in territories pertaining to traditional peoples and communities, manifested in social cartographies. These social cartographies reflect forms of knowledge appropriation about the territory that traditional peoples and communities possess, so that the reality that they wish to portray becomes evident. The ways in which they express their symbolic or territorial realities in these auto-cartographies establishes, by these means, a mechanism of confrontation and control of their own territories in opposition to information divulged by official agencies.
\end{abstract}

Keywords: Territory. Cartography. Power. 


\section{INTRODUÇÃO}

A interpretação do que é real e daquilo que expressa a realidade em contextos territoriais no processo de elaboração de mapas, não está relacionada a "tudo que existe dentro e fora da mente", como expressa o senso comum. A realidade está sujeita a campos de escolhas e especialmente na conjuntura de representação territorial, está atrelada a um jogo de interesses e relações de poder em torno de controle de territórios tradicionais. A realidade territorial, nesse sentido, é também uma construção, sobretudo política.

Há, contudo, a criação do imaginário em torno da delimitação de fronteiras, como reforça Benedict Anderson (2008) que perpassa pela forma como o Estado moldou seu poder em torno de instrumentos efetivos de dominação, especialmente se considerarmos o período colonial. A Antropologia, enquanto disciplina, é moldada nesse contexto histórico. E foi justamente essa estrutura de poder colonial que possibilitou o contato dos antropólogos nas décadas de 1920 a 40, como Malinowski (1992) em "Argonautas do Pacífico", Mayer Fortes-Evans Pritchard (1940) de "Sistemas políticos africanos" ou Evans-Pritchard (1940) em "Os Nuer" com seus campos de estudo.

Considerando o processo de elaboração de mapas no âmbito antropológico e político, já nesse período Malinoswski faz uso de mapas para representar as relações sociais e território dos Trombiandeses na Nova Guiné. Ele destaca formas de distribuições raciais espacialmente divididas entre as tribais locais e localização do arquipélago Trombiand. Obviamente as relações de interesses presentes na elaboração desse material cartográfico estão para além da contribuição científica, no entanto, Asad (1975) reforça que, apesar da contribuição da Antropologia para realização da manutenção da estrutura de poder representada pelo sistema colonial durante esse período, ela agia, mesmo que indiretamente, para o conhecimento de outras culturas. É nesse sentido que o autor defende que não há Antropologia com neutralidade política.

Nesse sentido, o que ocorre a partir da década de 70 na Antropologia, dentro de uma perspectiva metodológica, é ampliação de outros tipos de dados utilizados para construção de uma pesquisa etnográfica especialmente resultante de enfrentamentos em contextos de conflitos, aqui impostos por uma conjuntura mundial e que é decorrente de formas de atuações capitalistas em contextos coloniais. (ASAD, 1975). O jogo que se precede nesse processo é o jogo do poder.

Há de fato, como destaca Wolf (1989), modos de poder tático (cenário que as pessoas podem mostrar suas potencialidades e interagir com elas) e estrutural (organizam as configurações entre si, especificando o fluxo de energia existente) pertencente a dinâmicas que permeiam, sobretudo, nosso mundo capitalista. Por esse ângulo, Acserald (2015) destaca que os Estados Nacionais não atuavam mais como fronteiras defensivas de proteção, como faziam antes em contextos militares em defesa do território nacional, e sim como plataformas ofensivas para a economia mundial.

Dessa forma, pensando sobre novas formas de perceber a pesquisa etnográfica, farei neste artigo um esforço de análise para destacar as relações de poder e campos de disputas existentes no processo de elaboração de mapas considerados oficiais. E como essas relações estão articuladas em um jogo de interesse que se converte em controle de poder, principalmente quando se pensa em medidas adotadas pelo Estado e agências multilaterais em torno de questões que envolvem política e controle territorial de povos e comunidades tradicionais. Por outro lado, destacarei cartografias sociais que se contrapõem a mapas oficiais, dando visibilidade a povos e comunidades tradicionais, refor- 
çando discurso de pertencimento territorial e fortalecimento de identidade étnica analisada a partir de experiências de campo realizadas no âmbito do projeto Nova Cartografia Social da Amazônia (PNCSA).

Abordarei uma situação de pesquisa que resultou na elaboração de uma cartografia social da região ecológica do babaçu, com destaque para as quebradeiras de coco babaçu. Tal cartografia, apresenta comunidades invisíveis aos olhos do Estado e afetadas por grandes empreendimentos econômicos instalados em seus territórios. São comunidades que reforçam a construção de uma identidade coletiva e processos organizativos específicos atrelados à reivindicação de direitos negados a partir de demandas que não são viabilizadas pelo poder público. Isso se dá, nesse contexto, a partir de cartografias sociais que permitem a representação da realidade de luta, embate e pertencimento em seus territórios que não é apresentada em mapas reconhecidos como oficiais.

A situação analisa a cartografia "Nova Cartografia Social dos Babaçuais: Mapeamento Social da região ecológica do babaçu" resultado de pesquisa do projeto de mesmo nome. O mapa "Nova Cartografia Social dos Babaçuais" evidencia a denominada "Região ecológica do babaçu" destacando as diferentes formas organizativas articuladas por quebradeiras de coco babaçu, retratando realidades que não estão presentes em produções de cartografias dadas oficialmente. Ambas as cartografias sociais são parte de um processo de apropriação do saber construído pelos agentes sociais e suas formas organizativas ligadas aos seus interesses comuns, para reforçar mecanismos de uma luta coletiva.

Para tanto, pretendo ainda destacar ao longo deste artigo que os campos de disputa que se estruturam em torno do processo de elaboração de mapas pelo Estado vêmse apropriando, nos últimos anos, de técnicas cartográficas e políticas, pois à medida que emergem concomitantemente territorialidades específicas, há um processo de reconhecimento territorial legitimado pelo discurso de fala.Segato (2012), nessa perspectiva, faz um reforço nesse debate ao afirmar que os "outros", os "oprimidos", são sujeitos vivos na história, portanto, dispõem de autonomia. São grupos que se mobilizam em diferentes formas organizativas para reivindicar direitos que lhes são negados, redesenhando suas trajetórias de luta e relação de pertencimento a partir de cartografias sociais que expressam suas realidades.

\section{RELAÇÕES DE PODER E CONTROLE TERRITORIAL EM MAPAS OFICIAIS}

Em uma reflexão sobre cartografias e processos de territorialização, Acserald (2015) destaca que os mapas sempre tiveram papel fundamental nas definições da presença do Estado nos espaços modernos. Seja para controle na criação de jurisdição administrativa, seja para prescrever utilizações para o território como no zoneamento. Nesse sentido, o conhecimento que se tinha do território era inseparável da soberania do Estado, tornando o mapa um instrumento do discurso político a serviço desse mesmo Estado.

Ainda sobre a perspectiva de Acserald (2015), nas colônias os mapas serviram como instrumentos para deslegitimar comunidades indígenas e negras rurais. Nesse contexto, o Estado atuava com reformulador do espaço vigente, renomeava lugares naturais e cursos d'água sem realizar uma consulta prévia com quem ali habitava. Dessa forma, criava-se outro espaço, um espaço diferente do experienciado e reconhecido por comunidades que habitavam tais locais, criava-se um espaço de colonização. Aos indígenas não era dada a invisibilidade quanto a sua existência, porém eram descritos pelos portugueses 
como seres associados ao canibalismo ou figura pitoresca da floresta. Mas cabe lembrar que, posterior a esse momento, historicamente o monopólio de produzir mapas consistia num atributo das formações militares e dos famosos "colégios de cartógrafos”. (FARIAS; ALMEIDA, 2013).

Contudo, levando em consideração a região que tomarei como ponto de análise, limitarei a discorrer sobre dados de relações de poder que remetam especialmente à região denominada "região ecológica do babaçu" que cobre parte da Amazônia e do cerrado brasileiro para destacar processos de elaboração de mapas e elementos de dominação territorial que colocam em questão ação do Estado, agências multilaterais e grandes empreendimentos econômicos frente a territórios de povos e comunidades tradicionais.

Na década de 80, vigorava na Amazônia a agropecuária e o extrativismo, mas após esse período há uma migração de atividades para outro setor eminente: a mineração. Isso em decorrência, especialmente do Projeto Grande Carajás, planejado na região da Amazônia, com incentivos para exploração mineral que se iniciou na década de 70 e contemplou os estados do Maranhão, Tocantins e Pará. Contudo, nos últimos anos, especialmente após os anos 90, houve um crescimento das commodities em regiões estrategicamente pensadas para expansão. Com esse crescimento, houve também um novo formato de desenvolvimento que, com enclaves impostos pelo governo e a serviço de poderes capitalistas, tem afetado fortemente povos e comunidades tradicionais. (MESQUITA, 2015).

Para compor essa dinâmica capitalista com caráter regional, há uma associação de interesses que versa pelo econômico e político e que liga o Estado e grandes empreendimentos instalados na região, sobretudo, aqueles com grandes extensões de terra para o mercado de commodities. Nesse sentido, o governo, com todo seu aparato estratégico, investe em serviço de inteligência, na agroindústria e em projetos de infraestrutura que aqui são apresentados por rodovias, ferrovias e portos que favorecem a distribuição do produto final.

Isso é facilmente perceptível quando se pensa no Plano de Desenvolvimento Agropecuário do MATOPIBA, em parceria com INCRA e Embrapa (MDA e MAPA) (acrônimo criado com as iniciais dos estados do Maranhão, Tocantins, Piauí e Bahia) caracterizada como uma expansão de fronteira agrícola baseada em tecnologias modernas de alta produtividade. Mas que, para além disso, constitui parte de um plano de ação que agrega junto ao GITE (Grupo de Inteligência Territorial e Estratégica) um sistema de inteligência territorial estratégica exclusivo para o MATOPIBA, com a finalidade de compreender e descrever a região de atuação do plano. O sistema reúne acervos de dados numéricos, iconográficos e cartográficos, integrados em Sistemas de Informações Geográficas (SIG) em bancos de dados espaciais. (ESPAÇO TEMÁTICO MATOPIBA, 2018).

Os dados presentes em seus mapas contemplam informações de municípios pertencentes à região, quadro natural, agrário e agrícola, além de informações sobre infraestrutura ou aspectos socioeconômicos. Entretanto, em nenhum desses mapas há uma abordagem consistente sobre territórios quilombolas e indígenas inseridos na região e de como serão afetados pelo plano de ação. Esse tem sido um dos pontos de discussão sobre pautas reivindicativas de comunidades tradicionais, especialmente quilombolas e quebradeiras de coco babaçu que agregadas ao MIQCB (Movimento Interestadual das Quebradeiras de Coco babaçu) a respeito da ampliação da "nova fronteira agrícola" e consequentemente proibição de acesso aos recursos naturais em seus territórios tradicionais. 
Pensando nessa abordagem, cabe aqui refletir que a presença do capital numa determinada atividade ou região, historicamente, esteve associada à ocupação e controle do mercado, mas em todas elas, essa presença vem acompanhada de expropriação. Essas expropriações de terra são comandadas por grupos de investimentos que, em frentes diferentes, desorganizam e desarticulam comunidades tradicionais estabelecidas secularmente em suas terras, com territórios que são seus espaços de reprodução social. E o que antes era espaço de reprodução social, hoje passa a ser de reprodução do capital para grandes empreendimentos instalados na região. (MESQUITA, 2015).

Há um discurso de terras ilimitadas, mas há também o discurso de "espaços vazios", como ocorreu com os quilombolas em Alcântara - MA, quando ocorreu a implementação da base de foguetes. Para instalação da base de foguetes na cidade de Alcântara-MA e expansão do Centro de Lançamento de Alcântara (CLA), desde a década de 80 houve desapropriação de terras. (SEREJO LOPES, 2012). Durante o processo desconsiderou-se totalmente a presença de inúmeras comunidades remanescentes de quilombos, reforçando a ideia de "espaço vazio", e que hoje, apesar das conquistas, ainda lutam para terem seus direitos reconhecidos. Sobretudo, após avanço ilegal das negociações para cessão da Base Espacial de Alcântara aos Estados Unidos e outros países em 2017 e possíveis novos deslocamentos de comunidades quilombolas. (CARTA II SEMINÁRIO ALCÂNTARA, 2017).

Contudo, houve nos últimos anos um interesse em realizar formas de mapeamentos caracterizados como participativos ou comunitários em prol de um discurso que prega o "desenvolvimento sustentável" e o conceito de responsabilidade social de empresas que, com o apoio do Estado e como quesito dos manuais de agências multilaterais, incorporam esses mapeamentos a seus relatórios de desenvolvimento empresarial. Para Farias e Almeida (2013) a adoção dos mecanismos chamados de "participativos" confere legitimidade a estes projetos e programas. Embora sejam chamadas de "participativas" e "comunitárias" tais experiências consideram, entretanto, os agentes sociais como "indivíduos" cujo somatório resultaria na "comunidade". (FARIAS; ALMEIDA, 2013, p. 29)

Mas o que de fato ocorre são coalizões de interesses que têm como objetivo liquidar os direitos territoriais e controlar o acesso aos recursos naturais que dão sentido à sua existência. Exemplo disso está o mapeamento ${ }^{1}$ realizado pela empresa de exploração de gás natural no Maranhão, Parnaíba Gás Natural (PGN) com instalações localizadas nos municípios que afetam diretamente a comunidade quilombola Bom Jesus dos Pretos. (SILVA, 2016).

O processo cartográfico realizado pela empresa Parnaíba Gás Natural, apesar de reconhecer o conhecimento espacial e ambiental de populações locais, apresenta raízes metodológicas relativas ao mapeamento participativo ou colaborativo e embora haja uso demasiado do termo "cartografia social" em procedimentos cartográficos realizados pela empresa, o mapa que resulta de pesquisa que evidencia a área de influência dessa mesma empresa, promovendo um processo de elaboração cartográfica que favorece seus interesses sem levar em consideração a participação efetiva dos agentes sociais na elaboração das cartografias realizadas. Para Acselrad (2015):

O balanço das experiências sugerem que o protagonismo dos grupos ocorre quando o mapeamento surge como uma extensão do repertório de dinâmicas organizativas já previamente por eles experimentadas e não através de uma possibilidade de participação oferecida por instancias externas aos próprios grupos. (ACSELRAD, 2015, p. 22). 
Incorporada a essa discussão, em termos mais amplos, há inclusive, como destaca Almeida (2017) uma dessemantização do próprio uso da palavra "território", incorporado para designar programas, planos e projetos como território de cidadania ou cadastro territorial acompanhado de outra perspectiva espacial expressa em mapas oficiais. Com intenção que transcendem a sentidos práticos ambientais, extrativistas, políticas e fundiárias. Eles se apoiam em medidas "protecionistas", chamadas também de medidas táticas de defesa comercial, voltadas para o solo, recursos florestais e subsolo.

O mapa carrega na sua simbologia esse aspecto tático para ambos os lados, seja para resguardar e favorecer uma luta de interesses territoriais empresariais ou governamentais; seja para reivindicar direitos ou reforçar uma identidade étnica de povos e comunidades tradicionais. O mapa é o que Acserald destaca como sendo um "esquema de percepção do espaço que vai ganhando realidade na medida em que o conhecimento do território é também um meio de "produção deste território". (ACSERALD, 2015, p.13). Said (2011) da mesma forma reforça que há batalhas que não são desenvolvidas somente por soldados e canhões, mas por ideias, formas, imagens e imaginários. As disputas de poder sobre um território revelam uma disputa de poder através de mapas.

Para Scott (2000), quando se fala de resistência e poder, é perceptível que ambos os lados estão sempre tentando ganhar algo, de forma que as resistências existem e se colocam para exercitar algum tipo de poder. Há interesses de ambos os lados. No entanto, os caminhos que trilham para garantir o desenvolvimento ou ampliação da rede de agronegócio é regido por uma estratégia de redesenhar territórios tradicionais em mapas que não garantem para comunidades tradicionais seu reconhecimento legítimo.

\section{A REPRESENTAÇÃO DA REALIDADE DE COMUNIDADES TRADICIONAIS EM CARTOGRAFIAS SOCIAIS}

Desde a década de 80, como destaca Acserald (2015) que grupos vêm se organizando em torno da elaboração de mapas, grupos que até então não se viam nesse processo e não se imaginariam cartógrafos de suas realidades territoriais. O que mais impressiona desse processo articulado por uma cartografia social é que ele se dá de maneira coletiva e em torno de objetivos que permeiam pelo fortalecimento de uma identidade e direitos a territórios negados.

$\mathrm{O}$ acesso e uso de práticas cartográficas para ativar e rearticular disputas territoriais só foi possível a partir de acirramentos de tensões que emergiram entre comunidades tradicionais e grandes projetos de desenvolvimentos, afetando seus modos de vida e condições de acesso a seus recursos naturais. Os meios estratégicos para expansão do mercado de commodities e consequentemente uso de territórios tradicionais e ressignificação do mesmo, contribuíram para que articulações políticas fortalecidas por identidades coletivas se estruturassem nessa nova conjuntura.

Essas articulações representam um pluralismo social e político que constitui elemento para a construção da identidade que compõem essas comunidades tradicionais que se reconhecem enquanto quilombolas, ribeirinhas, agricultoras e quebradeiras de coco babaçu e que levam consigo pautas reivindicativas contestando as pressões de interesses de grandes empreendimentos sobre seus direitos territoriais. Essas articulações oferecem ainda condições de possibilidades para se pensar uma discussão em torno de uma "ambientalização" dos conflitos sociais. (LEITE LOPES, 2004). Essa "ambientalização" emerge 
de uma interiorização dos interesses comuns em um dado lugar, trazendo consigo o acesso aos recursos naturais e por políticas públicas que reconheçam as diferenças culturais e compreendam a cultura como um direito de cidadania.

Nesse sentido, a cartografia social acerca da qualbusco discorrer análise permeia questões que são resultados de desdobramentos políticos constituindo, dentro de suas representações políticas e articuladas, formas organizativas específicas. Ao transformarem cartografias sociais em objeto de ação política, geram meios para mobilizações e debates locais sobre situações adversas que perpassam seus territórios. Vê-se, portanto, nesta cartografia, que é também um mapa situacional, uma expressão também de resistência que transcende espaço e fronteiras oficiais, seja pela delimitação simbólica de seus territórios, seja pela identidade construída em torno dele, ou ainda pela realidade que buscam representar.

A cartografia social realizada por quebradeiras de coco babaçu no período de 2015 a 2016, na denominada "região ecológica do babaçu" reflete bem esse processo. A "região ecológica do babaçu", como reforça Almeida (2005) se destaca por agregar diferentes formas organizativas ligadas às quebradeiras de coco babaçu, sem obedecer necessariamente à incidência da palmeira de babaçu. O trabalho de campo foi realizado pelo projeto "Cartografia Social dos babaçuais: Mapeamento Social da Região Ecológica do Babaçu" delimitadoem seis regiões distintas que envolvem o norte do Estado do Piauí, Sudeste do Pará, norte do Pará e Oeste e Sudeste de Tocantins. No Maranhão, foram realizados três campos, a saber: região de Imperatriz, região dos Cocais e região da Baixada Maranhense.

O processo de elaboração da "Nova Cartografia social dos babaçuais"' (Figura 1), em parceria com o MIQCB (Movimento Interestadual das Quebradeiras de Coco Babaçu) perpassou dimensões amplas de discussões e processamento de informações por se tratar de uma área que corresponde a 18 mil hectares de floresta de babaçu, com áreas de maior ou menor densidade dapalmeira de babaçu presentes nos estados de maior incidência da palmeira: Piauí, Maranhão, Pará e Tocantins.

Figura 1

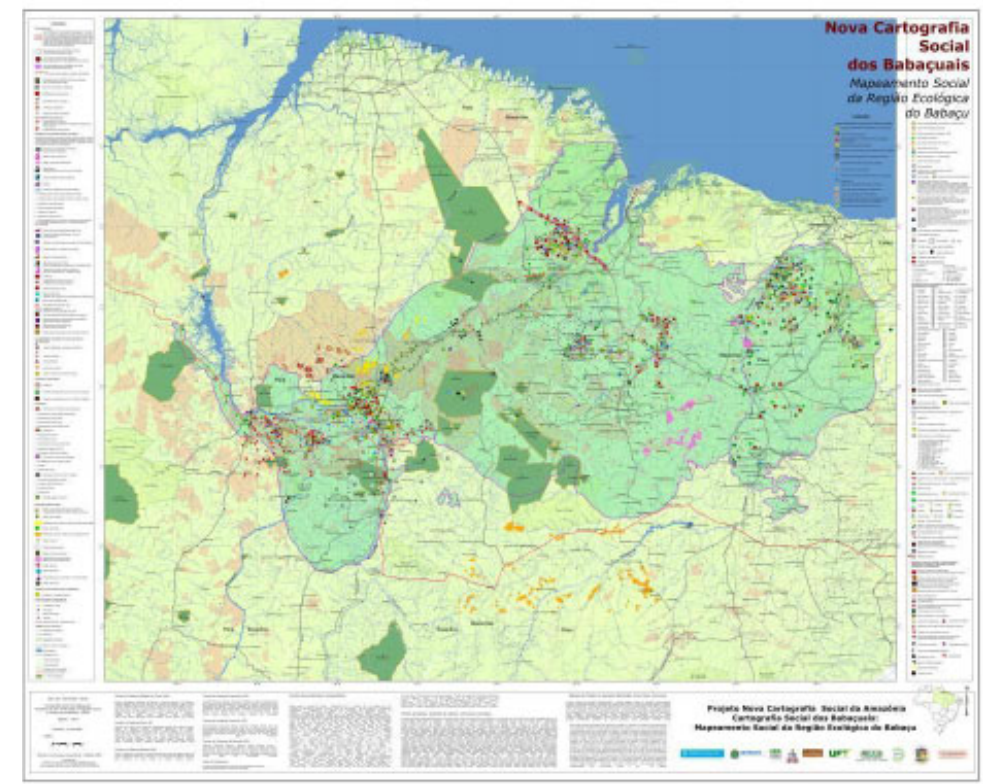

Fonte: Projeto Cartografia social dos babaçuais: Mapeamento social da região ecológica do babaçu, 2015. 
As informações de relevância social e política foram acrescentadas pelas quebradeiras de coco em um longo e minucioso processo de construção de pesquisa. Durante pesquisa de campo, as quebradeiras de coco babaçu elaboraram uma gama de informações que versavam por formas de organizações específicas, relações de trabalho e manutenção dos recursos naturais que lhes permitem reivindicar direitos que assegurem o livre acesso a esses recursos. As quebradeiras de coco babaçu entendem que são as palmeiras de babaçu que lhes asseguram a importância na reprodução física, social e cultural. À medida que expressam isso, entendem que a palmeira não se apresenta apenas como mero acessório do solo, ela faz parte da construção social e política das organizações nas quais as mulheres estão inseridas. (ALMEIDA, 2005).

Por se tratar de uma área que agrega diferentes situações de conflitos envoltos em agentes sociais unidas por uma identidade coletiva, mesmo que em determinados contextos possam ainda ser autodefinidas como quilombolas ou indígenas, o mapa das quebradeiras de coco babaçu traz um contexto de relações de dominação e de poder expressado pela implantação de grandes empreendimentos econômicos, juridicamente legalizados pelos aparatos do Estado, que arbitrariamente exercem o controle dos territórios. Agindo sempre em torno da opressão dos sujeitos que se reconhecem nesses mesmos territórios.

Nesse sentido, no âmbito do projeto "Cartografia Social dos Babaçuais: Mapeamento Social da Região Ecológica do Babaçu" houve a necessidade da criação de legendas que enfatizassem os territórios de pertencimentos com seus elementos essenciais, as formas organizativas atuantes na "região ecológica do babaçu", caracterizadas por regionais do MIQCB, Associação de artesãs, Associação de Jovem Rural, Unidades de produção de azeite de babaçu, Grupos Produtivos de Mulheres, Cantinas, Escolas Famílias, Forrageiras, Sindicatos, Centro de formações e União de mulheres; e listas com os grandes empreendimentos responsáveis por conflitos diretos com as quebradeiras de coco babaçu.

Parte desses conflitos destacados na cartografia social das quebradeiras de coco babaçu fazem parte da vida cotidiana dessas mulheres, que mesmo não estando na linha de frente dos embates articulados em organizações políticas, criam mecanismos estratégicos de defesa. É o que Scott (2000) faz um esforço para destacar ao afirmar que para muitos tipos de subordinados, especialmente os que sofrem a sujeição pessoal, a resistência informal e cotidiana é a estratégia mais eficaz nesse contexto de conflito presente. Para ele existe uma infrapolítica capaz de lidar com a política formal. A infrapolítica não é explícita, funciona na invisibilidade, mas é uma política de resistência. Resistência essa que transparece nas redes informais da família, vizinhos e amigos ao invés de adquirir uma organização formal, como entidades estabelecidas politicamente.

Ignorar esse tipo de política é ignorar que os grupos, independente da maneira como se organizam ou se articulam, apresentem uma vida ativa na política. É negar inclusive que os tais grupos sejam capazes de reinventar suas políticas diante dos mecanismos estratégicos impostos por grandes empreendimentos e pelo Estado para despolitizá-los.

Embora seja de conhecimento do Estado e secretarias governamentais que tratam de questões relacionadas aos Direitos Humanos e do Meio ambiente, as situações de conflitos existentes na "região ecológica do babaçu" são totalmente negligenciadas pelo poder público. Cada região de atuação das quebradeiras apresenta questões particulares quanto às tensões instaladas, mas em todas elas há uma forma mais expressiva de situação existente: a derrubada de palmeiras seja de babaçu, juçara ou carnaúba para criação de pastagens e produção de monocultura (eucalipto, soja, cana-de-açúcar). A negligência 
atribuída ao poder público diante de grandes projetos de desenvolvimento ou empreendimentos econômicos torna-se um mecanismo de violação de direitos de comunidades tradicionais e total descumprimento da Convenção 169 da Organização Internacional do Trabalho (OIT). O tratado aprovado pelo Congresso Nacional determina, obrigatoriamente, que povos e comunidades tradicionais tenham consulta prévia sobre qualquer medida que possa afetá-los.

A cartografia social elaborada ainda destaca situações de conflitos específicos das regiões pesquisadas, que versam por ameaças de morte contra quebradeiras, cercamentos dos babaçuais e proibição da coleta do coco. Estes conflitos são representados pela atuação de indústrias que provocam destruição dos recursos naturais, especulação imobiliária e concentração de terras, com destaque para empresa Suzano - papel e celulose instalada na região de Imperatriz - MA, provocadora de extensos desmatamentos das palmeiras de babaçu para plantio de eucalipto e teca. De forma mais incisiva, atua na desestruturação de organizações comunitárias com oferecimento de medidas compensatórias, ocorrendo o que Acserald (2017) destaca como sendo ocupação dos espaços públicos pelas corporações fornecendo como favor o que é de direito da população; e deslocamentos compulsórios de comunidades para expansão da área de plantio.

Na região dos cocais, com destaque para os municípios de Codó, Timbiras e Coroatá os conflitos se mostram a partir de outros personagens, mas com igual efeito devastador para quebradeiras de coco da região. O Grupo João Santos, com sede em Recife (PE), apresenta negócios que agregam plantações de cana-de-açúcar e extração de calcário, entra no Maranhão ainda na década de 70 com a produção de papel e celulose através da Indústria Itapagé S/A-Celulose, Papéis e Artefatos no município de Coelho Neto-MA, mas seus efeitos tornam-se mais evidentes na empresa Itapicuru Cimento Nassau, instalada no município de Codó-MA, por ainda estar em funcionamento com extração de calcário para produção de cimento e consequente derrubada de babaçuais.

A empresa FC Oliveira, por sua vez, localizada também no município de Codó, compra amêndoa de atravessadores; estes compram a amêndoa de quebradeiras de coco babaçu a baixo custo, para fins de abastecimento da fábrica de produtos de limpeza. Há, contudo, umainiciativa das mulheres em torno de formas organizativas na cidade para valorização do trabalho e fortalecimento do processo de construção de identidade a partir da criação de associações que articulam ações que beneficiam as mulheres que vivem da extração da amêndoa do coco babaçu. Durante o campo foram identificadas quatro associações no município de Codó-MA: Associação de Quebradeiras de Coco Babaçu no Bairro São Francisco; Associação de Quebradeiras de Coco Babaçu Nova Jerusalém; Associação de Quebradeiras de Coco da Travessa do Sol; Associação Comunitária dos Trabalhadores no Beneficiamento do Babaçu.

As fábricas de cerâmicas encontradas principalmente no norte do Piauí, Tocantins e Sudeste do Pará também agem nesse sentido, pois quando não são abastecidas com a casca do coco babaçu, abastecem seus fornos com o coco inteiro, impedindo o acesso das mulheres para a quebra do coco babaçu.

As situações de embate presentes na cartografia social das quebradeiras de coco babaçu refletem um mapa complexo, dinâmico e situacional. Tais situações evidenciam aspectos sociais e culturais e de pertencimento em seus territórios. Nesse sentido, ao elaborarem uma cartografia que de fato representa suas realidades, elas legitimam os discursos de apropriação de lugar construído em defesa de recursos naturais em oposição às produções cartográficas dadas oficialmente. O mapa "Nova Cartografia Social dos Babaçuais" confirma características pertinentes nos discursos dos agentes, dando ênfase a denominada 
"Região ecológica do babaçu", valorizando a organização social e políticas delas em torno do território, permitindo compreender a realidade dos agentes sociais envolvidos.

Deste modo, por apresentar esse aspecto complexo e expressivo da luta das quebradeiras de coco babaçu, a cartografia social elaborada passou a ser usada em diferentes situações de reivindicações junto ao poder público. A partir de reuniões articuladas com secretaria de direitos humanos e assembleias nos anos de 2015/2016 - Brasília com representantes do legislativo foi possível discutir sobre leis que favoreçam a preservação e acesso aos recursos naturais, a exemplo das leis municipais do babaçu livre já sancionada em treze municípios da "região ecológica do babaçu"; e propor políticas públicas que garantam reprodução social, econômica e políticas dessas mulheres.

A cartografia social das quebradeiras de coco babaçu ganhou visibilidade durante o lançamento do mapa em Julho/2015 que ocorreu em São Luís-MA ao ser divulgada em fontes midiáticas reconhecidas nacional e internacionalmente, a partir de coletivos, como Guardiões da Floresta e jornais de expressão internacional como The Guardian, Diário da Inglaterra;Reuters, Agência da Inglaterra; da Alemanha, o jornal FrankfurterAllgemeineZeitung e a empresa de radiodifusão Deutsche Welle; e a revista americana New Scientist. Toda essa visibilidade propiciou um reforço na luta pelo acesso e uso dos recursos naturais e acirrados conflitos presentes em seus territórios, negligenciados pelo poder público.

Por fim, entendo que os mapeamentos sociais, sobretudo, a cartografia "Nova Cartografia Social dos Babaçuais", são resultados de ações e participação ativa de agentes sociais que, na tentativa de assumir o controle sobre seus territórios, buscam refletir suas lutas, crenças, laços de solidariedade e suas formas de mobilização em mapas que carregam simbolismos e legitimidade, mas que expressam, sobretudo, a realidade que desejam representar.

\section{CONCLUSÃO}

O processo de compreender o poder é complexo e permeia níveis de discussões, sociológicas, políticas, psicológicas e antropológicas. O poder é uma espécie de produção de efeitos desejados e se refere, em certa medida, à capacidade de um indivíduo ou agência, transformar o comportamento de outro indivíduo. Esse esforço de entendimento também foi reforçado por Clastres (2014) quando este se refere ao poder econômico em conformidade ao político:

A relação de poder em uma sociedade precede e funda a relação econômica de exploração. Antes de ser econômica, a alienação é política. O econômico é uma derivação do político e o Estado determina o aparecimento de classes. Portanto, o que é decisivo em uma sociedade é a política e não o econômico. (CLASTRES, 2014, p. 192).

As relações de poder intrínsecas na elaboração de mapas expressa, sobretudo, uma relação política, de dominação e que por mais que esta esteja perdendo monopólio na arte de mapear, aquelas ainda exercem papel de opressão e dominação, resguardado sob um poder garantido pela soberania estatal. Há uma imbricada rede de relações que permeia o processo de elaboração de cartografias sociais, assim como há uma rede que norteia este mesmo processo para elaboração de mapas oficiais. A cartografia social, no entanto, vislumbra um objetivo maior. Não se limita às fronteiras pré-estabelecidas arbitrariamente. Dessencializam e desnaturalizam a noção de fronteiras construídas a partir de 
um processo histórico de colonização e adotam o que Barth (2000) expressa como fronteiras sociais, pois tais grupos apresentam dinâmicas que permitem transformações contínuas no tempo e no espaço.

Com isso, rompem com um procedimento imaginado de realidade que permeia os instrumentos de dominação expressos em mapas oficiais. Expressar a realidade através de papel, lápis e traços espaciais para povos e comunidades tradicionais aparece constituído por um conhecimento complexo, profundo e valioso, conhecimento este legitimado pela relação de pertencimento com o território ocupado tradicionalmente.

Finalizo enfatizando que mapas, simbolicamente ou não, refletem relação de poder. Por mais que as cartografias sociais possam conter em seus interiores linhas, pontos e polígonos que demarcam seus limites há, todavia, outra ligação que conecta pessoas, suas identidades, lugares e seus territórios que partem de relações de pertencimentos entre um e outro. O mapa pode se apresentar estático no papel, mas apresenta ao mesmo tempo dinâmicas e situações que transcendem o material, porque seus processos são evidenciados por mecanismos de fluidez.

\section{NOTAS}

${ }^{1}$ O mapa em questão pode ser encontrado na dissertação de mestrado de Jéssica Maria Barros Silva, intitulada "DAS ESTRATÉGIAS AOS DANOS: Estudo dos efeitos socioambientais da instalação do gasoduto Gavião Branco na comunidade Bom Jesus dos Pretos". Disponível em: $<$ http://www.ppgcspa. uema.br/wp-content/uploads/2017/03/disserta\%C3\%A7\%C3\%A3o-final-Copia-Teste-11.pdf>.

${ }^{2}$ A cartografia apresentada na figura 1, apresenta detalhes que não podem ser observados no tamanho ajustado para o artigo, contudo, destaco que o mesmo mapa pode ser encontrado para download na página Disponível em: $<\mathrm{http}: / /$ novacartografiasocial.com.br/mapa-nova-cartografia-social-dos-babacuais-mapeamento-social-da-regiao-ecologica-do-babacu/>.

\section{REFERÊNCIAS}

ACSERALD, Henri. O debate sobre cartografia e processos de territorialização - anotações de leitura/Introd. Cartografias Sociais, lutas por terra e lutas por território: um guia de leitura. Rio de Janeiro: IPPUR/UFRJ, 2015.

, Henri. O lugar e as possibilidades da política: sentidos da cartografia social. Rio de Janeiro/São Luís: Casa 08, 2017.

ALMEIDA, Alfredo Wagner Berno de. Os povos e comunidades tradicionais entre os novos significados de território e o rito de passagem da "proteção" ao "protecionismo". In Almeida. A.W. et.al. Agroecologia e diálogo de conhecimentos: Olhares de povos e comunidades tradicionais, movimentos sociais e academia Recife: UFRPE, 2017. p.118-131.

, Alfredo Wagner Berno de; MARTINS, Cynthia Carvalho; SHIRAISHI

NETO, Joaquim. Guerra Ecológica nos Babaçuais: o processo de devastação das palmeiras, a elevação do preço de commodities e aquecimento do mercado de terras na Amazônia. São Luís: MIQCB/BALAIOS TYPOGRAPHIA, 2005.

ANDERSON, Benedict R. Comunidades imaginadas: reflexões sobre a origem e a difusão do nacionalismo. São Paulo: Companhia das letras, 2008. 
ASAD, Talal. In. Anthropologyandthe Colonial Encounter. London: Ithaca Press, 1975.

BARTH. Fredrik. Os grupos étnicos e suas fronteiras. (S.I): Contracapa, 2000 CARTA ABERTA II SEMINÁRIO ALCÂNTARA: a base espacial e os impasses sociais. Alcântara, 2017.

CARTOGRAFIA SOCIAL DOS BABAÇUAIS Disponível em <http://novacartografiasocial.com.br/cartografia-social-dos-babacuais/>. Acesso em: 10 mar. 2018.

CLASTRES, Pierre. A sociedade contra o Estado. Pesquisa de Antropologia política. São Paulo: Cosasnaif, 2014.

ESPAÇO TEMÁTICO MATOPIBA. Disponível em: <https://www.embrapa. br/tema-matopiba/>. Acesso em: 04 mar. 2018.

FARIAS, Emmanuel Junior; ALMEIDA, Alffredo Wagner B.Nova Cartografia Social: territorialidades específicas e politização da consciência das fronteiras. Catálogo Povos e Comunidades Tradicionais. Manaus, 2013.

LEITE LOPES, José Sérgio (Coord.); Antonaz, Diana; Prado, Rosane; Solva, Gláucia (Org.). A ambientalização dos conflitos sociais: participação e controle público da poluição industrial. Rio de Janeiro: RelumeDumará, 2004. 334 p.

MESQUITA, Benjamin Alvino de. 2015. Grandes projetos de investimentos na Amazônia e as questões do desenvolvimento regional. In. Mesquita. B.A. et. al. Povos tradicionais em coalisão com estratégias empresariais no Maranhão e Pará. Manaus: UEA Edições,2015.

SAID, Edward. Cultura e imperialismo; tradução Denise Bottmann. São Paulo: Companhia das letras, 2011.

SCOTT, James C. Los dominados y le arte de laresistencia. Discursos ocultos. México: Editora Era, 2000.

SEGATO, Rita. Gênero e colonialidade: em busca de chaves de leitura e de um vocabulário estratégico descolonial. In: E-cadernos ces[Online], 2012.

SEREJO LOPES. Danilo da Conceição. A base espacial e as comunidades quilombolas de Alcântara. São Luis: Anais da 64a Reunião anual da SBPC, 2012.

SILVA, Jéssica Maria Barros. DAS ESTRATÉGIAS AOS DANOS: Estudo dos efeitos socioambientais da instalação do gasoduto Gavião Branco na comunidade Bom Jesus dos Pretos. Dissertação. (Mestrado em Cartografia Social e Política da Amazônia), Universidade Estadual do Maranhão, São Luis, 2016.

WOLF, Eric. Encarando o poder: velhos insights, novas questões. Universidade da Califórnia, 1989. 